Care: Jurnal Ilmiah Ilmu Kesehatan Vol .6, No.3,2018,hal 253-266

Tersedia online di https://jurnal.unitri.ac.id/index.php/care

ISSN 2527-8487 (online)

ISSN 2089-4503 (cetak)

\title{
Peranan Pendidikan Gizi Pada Guru Dalam Meningkatkan Asupan Sayur Dan
}

\section{Buah Anak Sekolah}

\author{
Verarica Silalahi ${ }^{1}$, Ronasari Mahaji Putri ${ }^{2}$, Nia Lukita Ariani ${ }^{3}$ \\ ${ }^{1,2,3}$ Program Studi Ilmu Keperawatan Universitas Tribhuwana Tunggadewi \\ e-mail: verasilalahi@rocketmail.com; putrirona@gmail.com
}

\begin{abstract}
Vegetable and fruit consumption in Indonesia is still low. Schools, through the role of teachers as central figures of education, are considered able to increase children's knowledge and have an impact on increasing the intake of vegetables and fruits in children. This study aims to analyze the increase of vegetables and fruits in children through nutrition education in teachers. The design of this study is quasy exsperiment with pre and post test. The sample of this study amounted to 6 teachers and 102 students in Merjosari 2 Public Elementary School, Merjosari 3 Public Elementary School and Merjosari 5 Public Elementary School. The intervention provided was nutritional education. Data on vegetable and fruit intake was taken using 24-hour food recall, while teacher knowledge was taken using a questionnaire. Data on vegetable and fruit intake were processed using Nutrisurvey.Wilcoxon test results showed that there was a significant difference in teacher's knowledge scores before and after the intervention $(p<0.05)$, there was no difference in students' vegetable intake, both in food portions and eating frequency $(p>0.05)$, there were significant differences in intake fruit of students, both in portion and frequency of eating $(p<0.05)$, and there were significant differences in the amount of students' nutrients (vitamin $A$, vitamin $C$, vitamin B1, and calcium) $(p<0.05)$. Need to provide nutritional education interventions to parents or guardians of students to increase the intake of vegetables and fruit students so that they can meet the daily nutritional adequacy.
\end{abstract}

Keywords : elementary school children; nutritional education; teacher; vegetables and fruits intake

\begin{abstract}
ABSTRAK
Konsumsi sayur dan buah di Indonesia masih rendah. Rendahnya konsumsi sayur dan buah berawal dari kegagalan pembiasaan sejak usia dini, termasuk di usia sekolah. Sekolah, melalui peran guru sebagai tokoh sentral pandidikan, dianggap mampu meningkatkan pengetahuan anak dan berdampak pada peningkatan asupan sayur dan buah pada anak. Penelitian ini bertujuan untuk menganalisis peningkatan sayur dan buah pada anak melalui pendidikan gizi pada guru. Rancangan penelitian ini adalah quasy exsperiment dengan pre and post test. Populasi penelitian adalah semua guru dan siswa yang ada di SD Negeri Merjosari 2, SD Negeri Merjosari 3 dan SD Negeri Merjosari 5. Sampel penelitian ini berjumlah 6 guru dan 102 siswa. Intervensi yang diberikan berupa pendidikan gizi. Data asupan sayur dan buah diambil menggunakan food recall 24 jam, sementara pengetahuan guru diambil menggunakan kuesioner. Data asupan sayur dan buah diolah menggunakan Nutrisurvey yang selanjutnya


bersama dengan data pengetahuan guru dianalisis menggunakan uji beda.Hasil uji Wilcoxon menunjukkan ada perbedaan yang bermakna skor pengetahuan guru sebelum dengan sesudah intervensi $(\mathrm{p}<0,05)$, tidak ada perbedaan asupan sayur siswa, baik secara porsi makanan maupun frekuensi makan ( $\mathrm{p}>0,05)$, ada perbedaan yang bermakna asupan buah siswa, baik secara porsi maupun frekuensi makan $(p<0,05)$, dan ada perbedaan yang bermakna jumlah zat gizi siswa (vitamin A, vitamin C, vitamin B1, dan kalsium) $(\mathrm{p}<0,05)$.Perlunya pemberian intervensi pendidikan gizi kepada orang tua atau wali murid untuk meningkatkan asupan sayur dan buah siswa sehingga bisa mencukupi Angka Kecukupan Gizi harian anak.

Kata Kunci : anak sekolah dasar; asupan sayur dan buah; guru; pendidikan gizi

\section{PENDAHULUAN}

Gizi yang optimal sangat penting untuk pertumbuhan normal, perkembangan fisik dan kecerdasan bayi, anak-anak, serta seluruh kelompok umur. Gizi baik memberi manfaat berat badan normal atau sehat, tubuh tidak mudah terkena penyakit infeksi, produktivitas kerja meningkat serta terlindung dari penyakit kronis dan kematian dini. Agar tubuh tetap sehat dan terhindar dari berbagai penyakit seperti penyakit kardiovaskular (penyakit jantung dan pembuluh darah, hipertensi dan stroke), diabetes serta kanker yang merupakan penyebab utama kematian di Indonesia, serta penyakit tidak menular terkait gizi, maka pola makan masyarakat perlu ditingkatkan kearah konsumsi gizi seimbang. Keadaan gizi yang baik dapat meningkatkan kesehatan individu dan masyarakat (Kemenkes, 2014a).
Di Indonesia, konsumsi sayur dan buah kurang sesuai dengan porsi yang dianjurkan. Hasil Riskesdas 2013, jumlah konsumsi sayuran rata-rata penduduk Indonesia $63,3 \%$ dari jumlah konsumsi yang dianjurkan dan pada buah-buahan $62,1 \%$ dari jumlah konsumsi yang dianjurkan. Pada kelompok usia $>10$ tahun sekitar 93,5\% mengonsumsi sayuran dan buah-buahan masih di bawah jumlah konsumsi yang dianjurkan (Kemenkes, 2014b). Didukung Bahria dan Triyanti (2010) menemukan bahwa sebesar $92,1 \%$ remaja kurang mengonsumsi buah dan 77,1\% kurang mengonsumsi sayur. Hermina dan Prihatini (2016) menemukan bahwa hampir semua penduduk Indonesia mengonsumsi sayur (94,8\%). Namun hanya sedikit yang mengonsumsi buah $(33,2 \%)$. Rerata konsumsi sayur penduduk 70,0 gram/orang/hari dan konsumsi buah 38,8 gram/orang/hari. Total konsumsi 
sayur dan buah penduduk 108,8 gram/orang/hari.

Bila dibandingkan dengan kecukupan yang dianjurkan menurut Pedoman Gizi Seimbang, konsumsi sayur dan buah tersebut masih rendah. Sesuai dengan Kemenkes (2014b), sebanyak 97,1\% penduduk kurang mengonsumsi sayur dan buah. Konsumsi sayur dan buah yang rendah dalam konteks gizi seimbang hampir berada di semua kelompok umur, baik di perkotaan maupun diperdesaan dan yang paling rendah adalah kelompok usia remaja (98,4\%).Tingginya angka kurang konsumsi sayur dan buah pada usia remaja kemungkinan telah dimulai sejak masa anak-anak. Salah satu Pesan Umum Gizi Seimbang (PUGS) yaitu banyak makan sayuran dan cukup buah-buahan (Kemenkes, 2014a) terbukti belum berhasil. Rendahnya pengetahuan menjadi satu faktor kurangnya konsumsi sayur pada anak. Senada dengan Putri,dkk (2017) yang menemukan pengetahuan anak usia 5-12 tahun (kandungan, jenis dan akibat kurang sayur) dalam kategori kurang di Yayasan Eleos Desa Sukodadi Kecamatan Wagir.

Gizi pada anak sekolah erat kaitannya dengan tumbuh kembang anak karena pada masa ini proses pertambahan fisik terjadi secara signifikan, yaitu pertambahan berat badan sekitar 1,8-2,7 kg per tahun dan pertambahan panjang badan sekitar 7,6 cm per tahun yang akan terus berlanjut memasuki tahap masa remaja (Departemen Gizi dan Kesehatan Masyarakat UI, 2014). Untuk mencegah timbulnya masalah gizi, diperlukan kegiatan sosialisasi yang tepat dan berbasis masyarakat. Salah satu bentuk kegiatannya adalah melalui pendidikan gizi yang disertai dengan penyuluhan gizi. Pendidikan gizi merupakan salah satu bagian dari Komunikasi Informasi dan Edukasi (KIE) Gizi yang bertujuan untuk memberikan informasi atau pesan yang berkaitan dengan gizi dari seseorang atau institusi kepada masyarakat sebagai penerima pesan melalui media tertentu dengan tujuan mengubah perilaku orang lain melalui pembentukan sikap dan perilaku (Departemen Gizi dan Kesehatan Masyarakat UI, 2014).

Dalam upaya mengubah perilaku, telah banyak penelitian yang menggunakan pendekatan pendidikan gizi sebagai intervensi dengan hasil yang baik. Dwiriani et al. (2011) dalam penelitiannya berhasil meningkatkan skor pengetahuan 
subyek setelah diberikan pendidikan gizi. Penelitian lainnya yang serupa adalah penelitian Candra et al. (2013), Nuryanto et al. (2013), Nurmasyita et al. (2015),) Buamona (2016), Putri, RM., Maemunah,N.(2017). Tidak sedikit pula pendidikan gizi yang disertai dengan penggunaan media juga memberikan hasil yang positif, seperti dalam penelitian Ekayanti et al. (2013), Briawan et al. (2013), dan Bica et al. (2016).

Agar kegiatan pendidikan gizi ini dapat dilaksanakan dengan optimal, maka perlu adanya kejelasan tugas dan tanggung jawab petugas dalam melaksanakan kegiatan tersebut disertai dengan peran aktif pemangku kepentingan, termasuk instansi lain seperti Pendidikan dan Kebudayaan (Kemenkes, 2014a). Sekolah merupakan tempat yang menyediakan kesempatan terbaik untuk mempromosikan gizi yang tepat. Promosi yang efektif akan praktik kesehatan, gizi dan aktivitas fisik sangatlah penting untuk mengurangi beban berat dari kelebihan berat badan, obesitas dan penyakit tidak menular (Rosso dan Arlianti, 2010).

Pendekatan pendidikan gizi dalam upaya meningkatkan pengetahuan dan asupan suatu zat gizi tertentu, seperti asupan sayur dan buah, belum pernah diberikan di SD Negeri Merjosari 2, SD Negeri Merjosari 3 dan SD Negeri Merjosari 5 yang dijadikan sebagai tempat penelitian. Berdasarkan profil Kota Malang, ketiga sekolah ini terletak di pinggir Kota Malang sekaligus di pinggir Kabupaten Malang sehingga memungkinkan tempat ini kurang mendapat informasi mengenai gizi, khususnya asupan sayur dan buah. Selain itu, berdasarkan studi pendahuluan yang dilakukan, ditemukan bahwa siswa/i yang ada di ketiga sekolah tersebut kurang mengonsumsi sayur dan buah dikarenakan ketidaksukaan kepada jenis makanan sayur dan kurangnya ketersediaan buah-buahan dalam keluarga.

\section{METODE PENELITIAN}

Rancangan penelitian ini adalah quasy experiment dengan pretest-posttest. Sebelum intervensi, dilakukan pretest pada guru mengenai pengetahuan yang berkaitan dengan asupan sayur dan buah, dan pada siswa/i dilakukan pengambilan asupan sayur dan buah melalui food recall 24 jam. Selesai intervensi, guru diberikan posttest, dan siswa/i dilakukan food recall 24 jam yang terakhir. Populasi dalam penelitian ini adalah semua guru dan siswa yang ada di tiga sekolah dasar yang menjadi tempat penelitian. Sampel guru dalam penelitian ini merupakan minimal wali kelas atau 
guru UKS, atau guru olahraga. Besar sampel siswa sebanyak 102 siswa dan 6 guru.

Data skor pengetahuan guru diambil menggunakan kuesioner sedangkan data asupan sayur dan buah diperoleh melalui wawancara langsung menggunakan food recall 24 jam. Data asupan sayur dan buah diolah menggunakan Nutrisurvey untuk memperoleh data zat gizi vitamin (vitamin $A$, vitamin $C$, vitamin $B 1$ dan vitamimn B6) dan mineral (besi, kalsium dan fosfor) yang selanjutnya diolah menggunakan SPSS versi 22. Untuk uji normalitas distribusi data skor pengetahuan gizi guru dan asupan sayur dan buah siswa/i, sebelum dan sesudah intervensi digunakan uji Kolmogorov-Smirnov.

Untuk melihat perbedaan skor pengetahuan guru sebelum dengan sesudah intervensi digunakan uji statistik parametrik t-berpasangan bila berdistribusi normal, dan sebaliknya digunakan uji statistik nonparametrik Wilcoxon bila tidak berdistribusi normal. Untuk melihat perbedaan asupan sayur dan buah berdasarkan porsi, frekuensi makan, dan jumlah zat gizi (vitamin dan mineral) sebelum dengan sesudah intervensi digunakan uji parametrik t-berpasangan bila berdistribusi normal, dan sebaliknya digunakan uji nonparametrik Wilcoxon bila tidak berdistribusi normal.

\section{HASIL}

Pendidikan guru 100\% sarjana. Rerata hasil pengetahuan gizi guru sebelum dilakukan intervensi sebesar $75,00 \pm 14,142$ dengan skor minimal 50 dan maksimal 55. Setelah dilakukan intervensi, rerata pengetahuan gizi guru meningkat menjadi 85,83 $\pm 15,623$ dengan skor minimal 90 dan maksimal 95.

Perbedaan skor pengetahuan gizi guru sebesar 10,83 poin. Hasil uji statistik non parametrik Wilcoxon membuktikan bahwa ada perbedaan yang bermakna rerata skor pengetahuan gizi guru antara sebelum dan sesudah intervensi pendidikan gizi ( Tabel 3).

Asupan sayur dan buah pada siswa (Tabel 4) dilihat berdasarkan porsi makanan, frekuensi makan dan jumlah zat gizi yang dimakan. Rerata asupan sayur dan buah berdasarkan porsi makan sayur tidak meningkat setelah diberikan intervensi pendidikan gizi pada guru (sebelum 61,56 $\pm 61,812 ; \quad$ sesudah $51,23 \pm 60,244)$. 
Tabel 1. Distribusi Frekuensi Karakteristik Guru Sekolah Dasar

\begin{tabular}{|c|c|c|}
\hline Karakteristik Guru & Jumlah & $\%$ \\
\hline $\begin{array}{l}\text { a. SD Negeri } \\
\text { Merjosari } 2\end{array}$ & 2 & 33,3 \\
\hline $\begin{array}{l}\text { b. SD Negeri } \\
\text { Merjosari } 3\end{array}$ & 1 & 16,7 \\
\hline $\begin{array}{l}\text { c. SD Negeri } \\
\text { Merjosari } 5\end{array}$ & 3 & 50,0 \\
\hline \multicolumn{3}{|l|}{ Jenis Kelamin } \\
\hline a. Laki-Laki & 2 & 33,3 \\
\hline b. Perempuan & 4 & 66,7 \\
\hline \multicolumn{3}{|l|}{ Status Pernikahan } \\
\hline a Menikah & 6 & 100,0 \\
\hline b Belum Menikah & 0 & 0,0 \\
\hline \multicolumn{3}{|l|}{ Agama } \\
\hline a. Islam & 5 & 83,3 \\
\hline $\begin{array}{l}\text { b. Kristen } \\
\text { Protestan }\end{array}$ & 1 & 16,7 \\
\hline Karakteristik Siswa & Jumlah & $\%$ \\
\hline a. SD Negeri & 36 & 2 \\
\hline \multirow{2}{*}{ b. SD Negeri } & 33 & 32,4 \\
\hline & & 32,4 \\
\hline $\begin{array}{l}\text { c. SD Negeri } \\
\text { Meriosari } 5\end{array}$ & 33 & \\
\hline \multicolumn{3}{|l|}{ Jenis Kelamin } \\
\hline Laki-laki & 51 & 50,0 \\
\hline Perempuan & 51 & 50,0 \\
\hline \multicolumn{3}{|l|}{ Pekerjaan Ayah } \\
\hline a. PNS/TNI/Polri & 11 & 10,8 \\
\hline b. Pegawai Swasta & 19 & 18,6 \\
\hline c. Petani/Pedagang & 13 & 12,7 \\
\hline d. Buruh & 31 & 30,4 \\
\hline e. Wiraswasta & 24 & 23,5 \\
\hline f. Tidak Bekerja & 4 & 3,9 \\
\hline \multicolumn{3}{|l|}{ Pekerjaan Ibu } \\
\hline a. PNS/TNI/Polri & 3 & 2,9 \\
\hline b. Pegawai Swasta & 4 & 3,9 \\
\hline c. Petani/Pedagang & 9 & 8,8 \\
\hline d. Buruh & 10 & 9,8 \\
\hline e. Wiraswasta & 14 & 13,7 \\
\hline $\begin{array}{l}\text { c. Tidak Bekerja } \\
\text { (IRT) }\end{array}$ & 62 & 60,8 \\
\hline
\end{tabular}

Sumber data: Penelitian, 2018

Hasil uji statistik membuktikan bahwa tidak terdapat perbedaan porsi makan sayur antara sebelum dengan sesudah intervensi $(\mathrm{p}>0,05)$. Demikian pula dengan frekuensi makan sayur tidak mengalami peningkatan setelah intervensi (sebelum 2,72 $\pm 0,958 ; \quad$ sesudah $2,58 \pm 0,939)$ dan secara statistik juga membuktikan tidak ada perbedaan rerata antara sebelum dengan sesudah intervensi $(\mathrm{p}>0,05)$.

Sementara itu, porsi makan buah mengalami peningkatan rerata (sebelum $175,94 \pm 503,761, \quad$ sesudah $192,55 \pm$ 157,632) dan secara statistik juga membuktikan ada perbedaan yang bermakna rerata porsi makan buah antara sebelum dengan sesudah intervensi $(p=0,000)$. Hal yang sama juga terjadi pada frekuensi makan buah yang mengalami peningkatan rerata (sebelum 2,04 $\pm 0,889$; sesudah $2,45 \pm 0,971)$ dan secara statistik membuktikan bahwa ada perbedaan yang bermakna rerata frekueni makan buah antara sebelum dengan sesudah intervensi.

Berdasarkan zat gizi yang paling banyak terkandung dalam sayur dan buah, dapat dilihat bahwa zat gizi yang mengalami perbedaan rerata yang bermakna antara sebelum dengan sesudah intervensi $(\mathrm{p}<0,055)$ adalah vitamin A (sebelum $318,50 \pm 556,732 ;$ dan sesudahnya 272,08 $\pm 657,704)$, vitamin C (sebelum 
Care: Jurnal Ilmiah Ilmu Kesehatan Vol .6, No.3,2018,hal 253-266

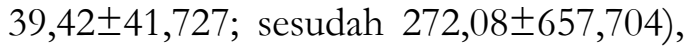

vitamin B1 (sebelum 0,10 $\pm 0,102$; sesudah
$0,14 \pm 0,107)$, dan kalsium $(52,87 \pm 89,612$;

sesudah $66,78 \pm 82,891)$.

Tabel 2. Distribusi Frekuensi Guru dan Siswa Berdasarkan Umur dan Lama Menjadi Guru

\begin{tabular}{lcccc}
\hline \multicolumn{1}{c}{ Karakteristik } & Min & Maks & Mean & SD \\
\hline Guru & & & & \\
Umur Guru & 32 & 58 & 46,83 & 11,771 \\
Lama Menjadi Guru & 8 & 37 & 24,33 & 12,160 \\
\hline Siswa & & & & \\
Umur Siswa & 9 & 13 & 10,34 & 0,652 \\
\hline
\end{tabular}

Sumber data: Penelitian, 2018

Tabel 3. Perbedaan Skor Pengetahuan Gizi Guru Sebelum dengan Sesudah Intervensi Pendidikan Gizi

\begin{tabular}{lllll}
\hline \multirow{2}{*}{ Variabel } & \multicolumn{2}{c}{ Skor Pengetahuan Gizi } & \\
& \multicolumn{2}{c}{ Guru } & Delta & $P$ \\
\cline { 2 - 3 } & Sebelum & Sesudah & & \\
\hline Mean & 75,00 & 85,83 & 10,83 & \\
Standar & 14,142 & 15,623 & 9,174 & \multirow{2}{*}{$0,041^{*_{a}}$} \\
Deviasi & & & & \\
Min & 50,00 & 90,00 & 0,00 & \\
Maks & 55,00 & 95,00 & 25,00 & \\
\hline
\end{tabular}

$*$ Signifikan

a Uji Wilcoxon

Tabel 4. Perbedaan Porsi Makan, Frekuensi Makan dan Jumlah Zat Gizi yang Dimakan Sebelum dengan Sesudah Intervensi Pendidikan Gizi

\begin{tabular}{|c|c|c|c|c|}
\hline Variabel & $\begin{array}{l}\text { Sebelum } \\
(\mathrm{X}, \mathrm{SD})\end{array}$ & $\begin{array}{c}\text { Sesudah } \\
(\mathrm{X}, \mathrm{SD})\end{array}$ & $\begin{array}{l}\text { Delta } \\
(\mathrm{X}, \mathrm{SD})\end{array}$ & $p$ \\
\hline Porsi Sayur & $61,56 \pm 61,812$ & $51,23 \pm 60,244$ & - & $0,108^{a}$ \\
\hline Porsi Buah & $175,94 \pm 503,761$ & $192,55 \pm 157,632$ & $18,33 \pm 527,86$ & $0,000^{*_{a}}$ \\
\hline Frekuensi Makan Sayur & $2,72 \pm 0,958$ & $2,56 \pm 0,939$ & - & $0,239^{a}$ \\
\hline $\begin{array}{l}\text { Frekuensi Makan Buah } \\
\text { Jumlah Zat Gizi }\end{array}$ & $2,04 \pm 0,889$ & $2,45 \pm 0,971$ & $0,41 \pm 1,10$ & $0,000^{* a}$ \\
\hline a. Vit A & $318,50 \pm 556,732$ & $272,08 \pm 657,704$ & - & $0,007^{* a}$ \\
\hline b. Vit C & $39,42 \pm 41,727$ & $67,45 \pm 63,811$ & $28,03 \pm 65,312$ & $0,000^{*}$ \\
\hline c. Vit B1 & $0,10 \pm 0,102$ & $0,14 \pm 0,107$ & $0,04 \pm 0,125$ & $0,002^{*_{a}}$ \\
\hline d. Vit B6 & $0,22 \pm 0,224$ & $0,22 \pm 0,206$ & - & $0,546^{a}$ \\
\hline e. Besi & $1,39 \pm 5,018$ & $1,322 \pm 4,832$ & - & $0,575^{a}$ \\
\hline f. Kalsium & $52,87 \pm 89,612$ & $66,78 \pm 82,891$ & $13,91 \pm 57,96$ & $0,022^{*_{a}}$ \\
\hline g. Fosfor & $42,13 \pm 42,554$ & $42,45 \pm 30,782$ & - & $0,942^{\mathrm{b}}$ \\
\hline
\end{tabular}

* Signifikan

a Uji Wilcoxon

b Uji t-Berpasangan 
PEMBAHASAN

\section{Pengetahuan Gizi Guru Sebelum dengan Sesudah Intervensi Pendidikan Gizi}

Pendidikan gizi merupakan suatu upaya untuk memperbaiki gizi masyarakat maupun perorangan (Sediaoetama, 2004a). Tujuan pendidikan gizi adalah untuk membangun kesadaran individu atau kelompok tentang pentingnya gizi bagi kehidupan sehingga diharapkan dapat mengubah sikap dan tindakan ke arah pemenuhan kebutuhan gizi (Proverawati dan Wati, 2014). Pembangunan kesadaran dimulai dari pembentukan pengetahuan yang benar tentang gizi. Intervensi pendidikan gizi yang diberikan kepada guru terbukti dapat meningkatkan pengetahuan gizi guru tentang tentang sayur dan buah. Hasil yang sama juga didapatkan pada penelitian Candra et al. (2013) yaitu pendidikan gizi yang diberikan mampu meningkatkan pengetahuan gizi subyek sebesar 20,06\%, sebesar 30 poin pada kelompok perlakuan penelitian Simanjuntak et al. (2016), sebesar 0,308 poin dari 8,38 poin pada penelitian Sartika (2012), dan sebesar 9,59 poin pada penelitian Nurmasyita et al. (2015).

Peningkatan skor pengetahuan gizi guru tidak lepas dari peran media yang digunakan. Booklet merupakan salah satu media pendidikan gizi yang dapat membantu penyampaian informasi kesehatan dan mempermudah penerimaan pesan kesehatan bagi klien atau masyarakat (Proverawati dan Wati, 2014). Penggunaan media pendidikan mampu meningkatkan pengetahuan subyek sebesar 4,78 poin pada penelitian Ekayanti et al. (2013), sebesar 10,2 poin pada penelitian Briawan et al. (2013) dan sebesar 5,16 poin pada penelitian Nuryanto et al. (2014).

Faktor pendidikan terakhir individu dan pengalaman juga berperan dalam penyerapan dan pemahaman informasi yang diberikan. Hasil penelitian menemukan bahwa seluruh guru merupakan lulusan strata 1 dan rerata lama menjadi guru 24 tahun (Tabel 2). Hal ini menunjukkan bahwa guru tergolong dalam kelompok berpendidikan tinggi dan sudah sangat berpengalaman dalam pendidikan dan pengajaran. Faktor ini mempermudah penyampaian intervensi pendidikan gizi tentang sayur dan buah. Individu yang berpendidikan tinggi lebih mudah memahami dan mencerna informasi sehingga bisa bersikap lebih baik dibandingkan individu yang tingkat pendidikannya rendah (Febrianto dan Rismayanthi, 2014). 
Asupan Sayur dan Buah Siswa Dilihat dari Porsi Makan, Frekuensi Makan dan Jumlah Zat Gizi yang Dimakan

Rendahnya porsi dan frekuensi makan sayur dibandingkan asupan buah (Tabel 4) dikarenakan sayur harus dimasak terlebih dahulu sementara buah dapat dimakan langsung. Ketersediaan jajanan rujak buah di sekolah membuat akses untuk mengkonsumsi buah lebih tinggi. Selain itu, karakter anak-anak lebih menyukai buah dibandingkan sayur sehingga menjadi tantangan tersendiri bagi orang tua untuk bijaksana dalam menyajikan makanan sayur agar dapat mengundang selera makan anak. Hasil penelitian ini sama dengan yang ditemukan oleh Young et al. (2013), yaitu secara signifikan, anak sekolah lebih banyak mengkonsumsi buah dibandingkan sayur $(\mathrm{p}<0,0001)$. Konsep diri anak khususnya motivasi diri sendiri agar mau makan sayur dan buah lebih banyak perlu dibangun untuk meningkatkan asupan sayur dan buah (Albani et al., 2018).

Asupan sayur dan buah berdasarkan porsi makanan dan frekuensi makan memengaruhi jumlah zat gizi yang masuk ke dalam tubuh. Rendahnya konsumsi sayur secara porsi dan frekuensi menyebabkan rendahnya pula beberapa jumlah zat gizi. Hal ini terlihat paling signifikan pada jumlah vitamin A. Rendahnya jumlah vitamin A dikarenakan pada saat food recall yang kedua, siswa ditemukan sedikit mengkonsumsi wortel yang merupakan sumber vitamin A. Rendahnya vitamin A juga disebabkan rendahnya porsi makan sayur. Vitamin A banyak terdapat dalam sayuran hijau (Sediaoetama, 2004b).

Sementara itu, terlihat peningkatan beberapa zat gizi lainnya seperti vitamin C, vitamin B1 dan kalsium. Peningkatan vitamin $\mathrm{C}$ dilihat dari meningkatnya konsumsi jeruk manis pada siswa ketika food recall yang kedua. Hasil yang sama didapatkan pada penelitian Wulansari (2009). Peningkatan vitamin B1 dikarenakan meningkatnya konsumsi sawi pada siswa. Sawi merupakan salah satu sayur yang memiliki kandungan vitamin B1 yang cukup tinggi. Peningkatan kalsium dikarenakan meningkatnya konsumsi bayam. Bayam merupakan salah satu sayur yang memiliki kandungan kalsium yang cukup tinggi (Sediaoetama, 2004b). Peningkatan ini menandakan bahwa pendidikan gizi yang diberikan kepada guru bermanfaat bagi siswa. Siswa cenderung mudah menerima ajaran gurunya dan meneruskannya kepada orang tua (Pudjiadi, 2003). Hasil penelitian ini 
juga menandakan bahwa masih rendahnya keragaman makan sayur dan buah pada siswa. Siswa cenderung mengkonsumsi sayur dan buah hanya pada satu jenis yang sama sehingga meningkatkan suatu zat gizi tertentu dan mengabaikan zat gizi lainnya. Hasil ini terlihat pada saat food recall yang pertama dan kedua. Padahal, usia sekolah dianjurkan untuk mengkonsumsi makanan yang beraneka ragam untuk memenuhi kebutuhan harian gizi mereka.

Kurangnya keragaman asupan sayur dan buah siswa dapat disebabkan oleh banyak faktor. Faktor keluarga dan lingkungan merupakan penyebab lebih 50\% terjadinya variasi konsumsi sayur dan buah pada anak sekolah (Gross et al., 2010). Anak tidak mau makan adalah keluhan paling banyak orang tua ketika berhadapan dengan jam makan anak. Hilangnya selera makan anak dapat disebabkan oleh anak dipaksa menghabiskan porsi makannya ketika ia mulai merasa kenyang. Selain itu, faktor emosi juga memengaruhi selera makan anak. Anak yang diberi kasih sayang orang tua secara cukup akan lebih mudah untuk menghabiskan makannya ketimbang anak yang tidak mendapatkan kasih sayang orang tua yang cukup (Pudjiadi, 2003). Faktor konsumsi sayur anak dipengaruhi oleh frekuensi dan porsi makan sayur orang tua sendiri serta praktik pemberian makan orang tua, terutama pada orang tua yang sangat lemah dalam mengontrol makanan anak (Kantali, 2016).

Faktor pertemanan juga berperan dalam menentukan asupan sayur dan buah anak sekolah. Karakteristik anak sekolah lebih suka mengikuti pola makan temantemannya seperti jajan goreng-gorengan, coklat, permen, es dan lainnya yang kurang bergizi (Proverawati dan Wati, 2014). Pola makan anak tidak terlepas dari budaya dalam keluarga. Keluarga dengan struktur kekuasaan dan punya pantangan tertentu terhadap suatu makanan akan membentuk pola makan anak seusai dengan kebiasaan keluarganya (Sediaoetama, 2004a; Pearson et al., 2009). Anggapan tentang belum pentingnya konsumsi sayur dan buah terlihat dari pengeluaran rumah tangga untuk konsumsi dua bahan makanan ini masih kecil dibandingkan pengeluaran untuk pembelian makanan dan minuman lainnya selain sayur dan buah, dan hampir sama dengan pengeluaran untuk pembelian tembakau dan sirih (Aswatini et al., 2008; Attorp et al., 2014).

Faktor pengetahuan ibu sebagai penyedia makanan di rumah dapat menjadi salah 
satu faktor yang memengaruhi masih rendahnya asupan makanan terutama sayur pada siswa kendatipun pendidikan gizi sudah diberikan kepada guru. Umumnya, masyarakat telah mengetahui pentingnya konsumsi sayur dan buah, namun belum memiliki pemahaman yang dalam sehingga tidak menjadi motivasi yang kuat bagi ibu dalam menyediakan sayur dan buah serta mengajak anak mereka untuk makan sayur dan buah (Aswatini et al., 2008; Wulansari, 2009). Ibu yang tidak mempunyai pengetahuan yang baik tentang prinsip gizi seimbang akan sulit memilih dan menyediakan makanan yang sesuai dengan kebutuhan gizi anaknya (Febrianto dan Rismayanthi, 2014; Sartika, 2012).

Faktor ekonomi keluarga akan memengaruhi ketersediaan makanan dalam keluarga sehinga secara langsung juga berpengaruh pada asupan makanan anak (Sediaoetama, 2004a). Siswa yang berasal dari keluarga dengan ketahanan pangan rendah secara ekonomi paling sedikit mengkonsumsi sayur (Grutzmacher dan Gross, 2011). Keluarga dengan penghasilan rendah biasanya akan menyediakan makanan apa adanya sehingga pertimbangan kebutuhan zat gizi yang dibutuhkan anak menjadi terbengkalai. Begitu sebaliknya, keluarga dengan penghasilan tinggi akan menyediakan makanan yang lengkap secara jumlah dan kandungan zat gizi (Febrianto dan Rismayanthi, 2014). Ketersediaan dan keterjangkauan sayur dan buah di rumah merupakan bukti paling kuat terhadap asupan sayur dan buah anak termasuk pola makan sayur dan buah orang tua serta asupan sayur dan buah ibu (Ong et al., 2017; Pearson et al., 2009; Wyse et al., 2015).

Anak yang berasal dari keluarga dengan tingkat pendidikan yang baik cenderung mengkonsumsi makanan yang sehat dikarenkan tingkat pemahaman orang tua yang mengetahui makanan terbaik bagi anaknya (Febrianto dan Rismayanthi, 2014; Pearson et al., 2009). Tingkat penghasilan keluarga ditentukan dari jenis pekerjaan orang tua (Pearson et al., 2009). Hasil penelitian ini menemukan bahwa sebanyak 30,4\% ayah siswa memiliki pekerjaan sebagai buruh dan sebanyak 60,8\% ibu siswa merupakan Ibu Rumah Tangga atau tidak bekerja (Tabel 1).

Masih rendahnya asupan sayur dan buah anak sekolah tidak terlepas dari peran guru. Untuk meningkatkan asupan sayur dan buah anak sekolah, guru 
membutuhkan tiga komponen, yaitu informasi, motivasi, dan kemampuan mengubah perilaku. Informasi yang didapatkan dari pendidikan gizi, juga harus disertai dengan penerimaan diri sebagai orang tua di sekolah (motivasi) dan tersedianya praktik hukuman-hadiah (kemampuan mengubah perilaku) (Mita et al., 2013). Penelitian ini hanya terbatas pada penyampaian informasi tentang sayur dan buah, serta belum terkandung prinsip memotivasi dan kemampuan mengubah perilaku melalui praktik hukuman-hadiah.

\section{KESIMPULAN}

a. Ada perbedaan yang bermakna antara skor pengetahuan gizi guru sebelum dengan sesudah diberikan intervensi

b. Meskipun tidak terjadi peningkatan asupan sayur, namun terjadi peningkatan asupan buah pada siswa dari segi porsi makanan, frekuensi makan dan jumlah zat gizi (vitamin A, vitamin $\mathrm{C}$, vitamin B1, dan kalsium) yang dikonsumsi

Direkomendasikan perlu pemberian pendidikan gizi kepada seluruh guru yang ada di Sekolah Dasar sehingga dapat menjangkau seluruh siswa/I, perlu penambahan waktu intervensi kepada guru sehingga guru dapat menggali lebih dalam tentang sayur dan buah, perlu penjadwalan khusus dan pengawasan secara langsung ketika guru memberikan pendidikan gizi terkait sayur dan buah pada siswa/I, perlu melihat pengetahuan siswa/i tentang sayur dan buah setelah intervensi pendidikan gizi diberikan kepada guru, intervensi pendidikan gizi kepada orang tua/ wali murid pada penelitian mendatang akan membantu meningkatkan asupan sayur pada anak sekolah

\section{REFERENSI}

Albani, V., Butler, L.T., Traill, W.B., dan Kennedy, O.B. (2018). Understanding Fruit and Vegetable Consumption in Children and Adolescent: the Contributions of Affect, Self-Concept and Habit Strength. Appetite, 120(1): 398-408.

Aswatini, Noveria, M., dan Fitranita, (2008). Konsumsi Sayur dan Buah di Masyarakat dalam Konteks Pemenuhan Gizi Seimbang. Jurnal Kependudukan Indonesia, 3(2): 97-119.

Attorp, A., Scott, J.E., Yew, A.C., Rhodes,R.E., Barr, S.I., dan Naylor, P.J. (2014). Association Between Socioeconomic, Parental and Home Environment Factors and Fruit and Vegetable Consumption of Children in Grades Five and Six in British Columbia Canada. BMC Public Health, 14(1): 150.

Bahria dan Triyanti. (2010). Faktor-Faktor yang Terkait dengan Konsumsi Buah dan Sayur pada Remaja di 4 SMA Jakarta Barat. Jurnal Kesehatan Masyarakat, 4(2): 63-71.

Bica, L.A., Jamelske, E.M., dan Lagorio, C.H. (2016). Increasing Fruit and Vegetable Consumption During 
Elementary School Snack Periods Using Incentives, Prompting and Role Modeling. The Journal of Child Nutrition \& Management, 40(2): 1-13.

Briawan, D., Ekayanti, I., dan Koerniawati, R.D. (2013). Pengaruh Media Kampanye Sarapan Sehat Terhadap Perubahan Pengetahuan, Sikap, dan Kebiasaan Sarapan Anak Sekolah Dasar di Kabupaten Bogor. Jurnal Gizi dan Pangan, 8(2): 115-122.

Buamona, E. (2016). Pengarub Pemberian Pendidikan Giri melalui Buku Saku dan Ceramah terhadap Pengetabuan Buah dan Sayur pada Anak Sekolah Dasar. Tesis. Universitas Sebelas Maret.

Candra, A.A., Setiawan, B., dan Damanik, M.R.M. (2013). Pengaruh Pemberian Makanan Jajanan, Pendidikan Gizi, dan Suplementasi Besi terhadap Status Gizi, Pengetahuan Gizi, dan Status Anemia pada Siswa Sekolah Dasar. Jurnal Giri dan Pangan, 8(2): 103-108.

Departemen Gizi dan Kesehatan Masyarakat UI, (2014). Gizi dan Kesehatan Masyarakat. Jakarta: PT Raja Grafindo Persada.

Ekayanti, I., Briawan, D., dan Destiara, I. (2013). Perbedaan Penggunaan Media Pendidikan Terhadap Perubahan Pengetahuan dan Sikap Ibu Dalam Sarapan Anak Sekolah Dasar di Kabupaten Bogor.Jurnal Giži dan Pangan, 8(2): 109-114.

Febrianto, I.D., dan Rismayanthi, C. (2014). Hubungan Tingkat Penghasilan, Tingkat Pendidikan dan Tingkat Pengetahuan Orang Tua tentang Makanan Bergizi dengan Status Gizi. Medikora, 13(1): $1-13$.

Gross, S.M., Pollock, E.D., dan Braun, B. (2010). Family Influence: Key to Fruit and Vegetable Consumption among Fourth-and Fifth-Grade Students. J Nutr Educ Behav, 42(4): 235-241.
Grutzmacher, S., dan Gross, S. (2011). Household Food Security and Fruit and Vegetable Intake among LowIncome Fourth -Graders. J Nutr Educ Behav, 43(6): 455-463.

Hermina, dan Prihatini S. (2016). Gambaran Konsumsi Sayur dan Buah Penduduk Indonesia dalam Konteks Gizi Seimbang: Analisis Lanjut Survei Konsumsi Makanan Individu (SKMI) 2014. Buletin Penelitian Kesehatan, 44(3): 205 - 218.

Kantali, M. (2016). The Influence of Parental Feeding Practices on the Consumption of Fruit and Vegetables in Preschool-Aged Children. Clinical Nutrition ESPEN, 13 (1): e55.

KementerianKesehatan RI. (2014a). Peraturan Menteri Kesehatan Republik Indonesia Nomor 41 Tabun 2014 Tentang Pedoman Giri Seimbang. Jakarta.

Kementerian Kesehatan RI. (2014b). Riset Kesehatan Dasar 2013. Jakarta.

Mita, S.C., Li, E., dan Goodell, L.S. (2013). A Qualitative Investigation of Teachers' Information, Motivation, and Behavioral Skills for Increasing Fruit and Vegetable Consumption in Preschoolers. J Nutr Educ Behav, 45(6): 793-799.

Nurmasyita, Widjanarko, B., dan Margawati, A. (2015). Pengaruh Intervensi Pendidikan Gizi Terhadap Peningkatan Pengetahuan Gizi, Perubahan Asupan Zat Gizi dan Indeks Massa Tubuh Remaja Kelebihan Berat Badan.Jurnal Gizi Indonesia, 4(1): 38-47.

Nuryanto, Pramono, A., Puruhita, N., dan Muis, S.F. (2014). Pengaruh Pendidikan Gizi Terhadap Pengetahuan dan Sikap Tentang Gizi Anak Sekolah Dasar. Jurnal Gizi Indonesia, 3(1): 32-36.

Ong, J.X., Ullah, S., Miller, J., dan Leslie, E. (2017).Relationship Between the Home Environment and Fruit and 
Vegetable Consumption in Children Aged 6-12 Years: a Systematic Review. Public Health Nutr, 20(3): 464-480.

Pearson, N., Biddle, S.J., dan Gorely, T. (2009). Family Correlates of Fruit and Vegetable Consumption in Children and Adolescents: a Systematic Review. Public Health Nutr, 12(2): 267-283.

Proverawati, A dan Erna Kusuma Wati. (2014). Ilmu Gizi Untuk Keperawaran dan Giri Kesehatan. Yogyakarta: Muha Medika.

Pudjiadi, S. (2003). Ilmu Gizi Klinis pada Anak. Jakarta: Balai Penerbit FKUI.

Putri, R., Susmini, S., \& Hadi, H. (2017). Gambaran Pengetahuan Sayur Anak Usia 5-12 Tahun Di Yayasan Eleos Indonesia Desa Sukodadi Kecamatan Wagir Kabupaten Malang. Jurnal Ilmu Keperawatan, 5(1), pp. 74-80. Retrieved from http://jik.ub.ac.id/index.php/jik/a rticle/view/121

Putri,RM., Maemunah,N.(2017). The Role of Education in Improving the Knowledge of Children about the Importance of Vegetables. Jurnal Keperawatan.

Volume 8(1).Universitas Muhammadiyah Malang. http://ejournal. umm.ac.id/ index. Php keperawatan/article/view/4018

Rosso, J.M.D., dan Arlianti, R. (2010). Investasi untuk. Kesehatan dan Giri Sekolah di Indonesia. Bec-TF.

Sartika, R.A.D. (2012). Penerapan Komunikasi, Informasi, dan Edukasi Gizi terhadap Perilaku
Sarapan Siswa Sekolah Dasar. Jurnal Kesehatan Masyarakat Nasional, 7 (2): 76-82.

Sediaoetama, A.D. (2004a). Ilmu Giži untuk Mahasiswa dan Profesi Jilid I. Jakarta: Penerbit Dian Rakyat.

Sediaoetama, A.D. (2004b). Ilmu Gizi untuk Mahasiswa dan Profesi Jilid II. Jakarta: Penerbit Dian Rakyat.

Simanjuntak, R.R., Kartasurya, M.I., dan Rosidi, A. (2016). Pengaruh Pesan Gizi Singkat dan Pendidikan Gizi terhadap Praktik Makan Pasien Rawat Inap di Rumah Sakit Umum Daerah Salatiga. Junal Giri Indonesia, 4(2):120-124.

Wulansari, N.D. (2009). Konsumsi serta Preferensi Buab dan Sayur pada Remaja SMA dengan Status Sosial Ekonomi yang Berbeda di Bogor. Institut Pertanian Bogor.

Wyse, R., Wolfenden, L., dan Bisquera, A. (2015). Characteristics of the Home Food Environment that Mediate Immediate and Sustained Increases in Child Fruit and Vegetable Consumption: Mediation Analysis from the Healthy Habits Cluster Randomised Controlled Trial. Int $J$ Behav Nutr Phys Act, 12(1):118.

Young, K.D., Snelling, A., Maroto, M., dan Young, K.A. (2013). Consumption of Fruits and Vegetables in Middle School Students Following the Implementation of a School District Wellness Policy. The Journal of Child Nutrition and Management, 37(2): 1-6. 